\title{
A cultura na mente e nas sociedades
}

\author{
Lívia Mathias Simão* \\ Vívian Volkmer Pontes
}

Universidade de São Paulo, Instituto de Psicologia, Departamento de Psicologia Experimental. São Paulo, SP, Brasil

\section{Resenha de: Valsiner, J. (2012). Fundamentos da psicologia cultural: mundos da mente, mundos da vida. Porto Alegre, RS: Artmed.}

Fundamentos da psicologia cultural: mundos da mente, mundos da vida representa um dos resultados do trabalho construtivo e sistemático que Jaan Valsiner vem desenvolvendo ao longo de seu percurso acadêmico-científico, segundo dois eixos complementares, o teórico-metodológico e o epistemológico, em interlocução com autores clássicos e contemporâneos da psicologia e de áreas de fronteira, em especial a antropologia, a sociologia, a história e a semiótica.

No âmbito epistemológico, Valsiner busca delinear os fundamentos de uma psicologia cultural que, no âmbito teórico-metodológico, a concebe como alicerçada em processos semióticos.

Metateoricamente, podemos dizer que o livro representa um dos pontos de viragem no percurso de Valsiner como teórico da psicologia cultural. Esse percurso pode ser caracterizado, em seu início, como uma abordagem cultural ao desenvolvimento humano - como em Human development and culture (1989), para desdobrar-se em uma abordagem à cultura no desenvolvimento humano, como em The guided mind (1998), Culture and human development (2000), Culture in mind and societies (2007), cuja tradução é objeto desta resenha, e em $A$ guided science (2012). Valsiner continua aprofundando-se nessa direção, fazendo mais recentemente um convite explícito para que o acompanhemos nesse percurso, An invitation to cultural psychology (2014).

\section{A cultura na mente e nas sociedades}

Tomada de maneira geral, a questão que orienta Fundamentos da psicologia cultural é a de como a cultura está presente no sentir, pensar e agir humanos. Tomada nos termos da construção teórico-metodológica de Valsiner, essa questão aborda como a cultura, entendida como sistema semiótico de regulação, se faz presente, por um lado, no processo de construção e organização mental pessoal e, por outro, na constante criação e recriação social humana.

* Endereço para correspondência: limsmao@usp.br
Partindo de sua concepção de desenvolvimento, que implica movimento e transformação, o autor busca enfrentar o desafio de uma psicologia cultural que, na atualidade, se desenvolva, ela mesma, como ciência interdisciplinar do desenvolvimento individual e social.

É à articulação entre o pessoal e o coletivo, que possibilita a emergência da novidade, que Valsiner se dedicará nesse livro; questão e articulação, de resto, já anunciadas e trabalhadas em suas obras anteriores ${ }^{1}$, mas que aqui se acrescentam no desafio de avançar no âmbito teórico-metodológico da psicologia cultural como ciência sistêmica, qualitativa e, sobretudo, idiográfica.

Valsiner propõe a psicologia cultural como "uma disciplina que é geral quanto ao conhecimento básico, ao mesmo tempo em que representa particulares humanos em toda a sua riqueza" (p. ix, no prefácio do autor à edição brasileira). Apoia-se, para tanto, na semiótica de Charles Pierce e na sematologia de Karl Bühler, teóricos que fundamentam suas ideias desde trabalhos anteriores. Ao mesmo tempo, procura não se apartar da experiência humana vivida, foco fenomenológico da obra, conforme assinalado por ele mesmo (p. ix, prefácio do autor à edição brasileira). Nesse sentido, devem ser compreendidas as diversas e ricas análises de situações experienciais às quais ele se dedica nessa monografia, tais como as relacionadas à peregrinação religiosa, ao trabalho forçado, à mobilidade geográfica, política e social, à saúde e aos medos de doenças, ao valor do segredo, às formas de casamentos e formações familiares.

"O resultado é outra construção de uma teoria psicológica que reivindica ser científica. [...] e universal, diante de fenômenos psicológicos completamente singulares" (p. ix, prefácio do autor à edição brasileira, itálico nosso).

Esse resultado construtivo, a que Valsiner se refere como outra construção, é outro justamente quanto às

1 Veja, por exemplo, The guided mind (1988), em que a experiência humana é tomada como realidade subjetiva culturalmente organizada e constantemente recriada de modo pessoal, em uma articulação entre as tradições do personalismo, de Stern, e da psicologia histórico-cultural de Vygotsky e Luria. 
formas de relação pessoa-cultura que postulará, afastando-se de proposições monológicas da relação entre acontecimentos pessoais e sociais, tais como aquelas em que "a pessoa pertence à cultura", como na psicologia transcultural, e também daquelas em que "a cultura pertence à pessoa", como na antropologia social. Na dialogia de Valsiner, a cultura pertence ao sistema psicológico individual, que se constrói pelos processos de internalização e externalização - aqui aparece a perspectiva de Lev Vygostsky - em um constante movimento de mútua constituição entre acontecimentos pessoais e sociais - aqui se mostra a perspectiva de bidirecionalidade dos processos de socialização, que 0 autor traz de suas obras anteriores.

Essas ideias são postas no Capítulo 1, em que Valsiner se dedica não apenas à sua postulação, mas também e principalmente em situá-las criticamente no âmbito das noções de cultura contemporâneas, em explicitar sua filiação teórico-metodológica e em argumentar em favor delas por meio de suas implicações para a articulação entre os âmbitos pessoal e social da vida humana. Nesse capítulo inicial já apresenta os constructos formadores de sua proposta da cultura como semiose, em que a noção de ambiguidade é central:

Se a cultura deve ser explicada pela semiose, a noção de ambiguidade está necessariamente, por conseguinte, no centro de todos os nossos construtos teóricos, do mesmo modo que desempenha um papel central em nossas experiências de vida (p. 49).

Ancorado no que ele mesmo denomina de "bases semióticas da psicologia cultural" prossegue, nos Capítulos 2 a 7, com uma complexa articulação entre os âmbitos pessoal e coletivo, onde cada proposição é geneticamente formativa da outra, e todas sistemicamente integradas na questão-chave do livro: "como os seres humanos vivem em uma sociedade e . . . como a sociedade 'vive no interior' dos seres humanos" (p. 67).

Nesses capítulos, diante das formulações teóricas que vai apresentando, são desdobradas implicações epistemológicas, metodológicas e éticas de suas escolhas na direção desta ou daquela psicologia, nesta ou naquela fronteira com as ciências, a história e a semiótica.

O Capítulo 2 é, nessa perspectiva, central. Nele Valsiner traz à tona e explicita sua noção de sociedade, que vem cunhando principalmente dentro de tradições da psicologia social de campo, remetendo a Kurt Lewin, da psicologia das representações sociais, com Moscovici, e da psicologia genético-cultural, com Heinz Werner.

Nessa altura, define sociedade como uma abstração conceitual, uma história mítica coletivamente criada e partilhada, que funciona como um signo (do tipo campo), com impacto orientador sobre a vida das pessoas. A sociedade é, assim, uma teia mitológica, construída e reconstruída pelas próprias pessoas nela imersas - que cria condições reais ou circunscreve suas próprias vidas, orientando seu próprio existir. Aqui é reconhecida a convergência das proposições de Valsiner com as de Boesch (1991), em sua teoria da ação simbólica, a que Valsiner dedicará em parte no Capítulo 5.

A feitura dessa teia mitológica é processual; temporal. Ela é construída e reconstruída continuamente, em tempo irreversível, o que confere caráter de momentaneidade, singularidade e novidade - como em Bergson, talvez a influência filosófica mais profunda em Valsiner. Fabricados os significados, eles tendem, por sua vez, a se estabilizarem pelos processos individuais de percepção e atenção seletivas e de diferenciação semiótica. Essa estabilização é, por sua vez, altamente funcional para que as pessoas lidem com a incerteza do futuro: "O futuro é incerto - e o passado está constantemente sendo reconstruído à medida que enfrentamos a incerteza do futuro" (p. 109). Reconhece-se aqui a marca de William James.

A questão da emergência da novidade - um problema conceitual básico em todas as ciências - é, então, objeto de reflexão do autor: como "algo novo, previamente desconhecido, emerge sob a base do previamente estabelecido?" (p. 112). E ele mesmo responde: o "nascimento do presente próximo" ocorre no domínio psicológico, a partir da tensão criada pela interseção entre a insistência seletiva daquilo que vem do passado como algo que efetivamente se deu, e a incerteza dos eventos futuros. "Os signos são criados para superar essa tensão" (p. 113).

Essa é a discussão que perpassará todo o Capítulo 3 , inscrevendo a relação sociedade-pessoa-cultura, proposta por Valsiner, na dinâmica temporal.

No Capítulo 4, Valsiner circunstancia as proposições dos três primeiros capítulos por meio de uma análise da organização dos grupos de parentesco, famílias e formas de casamento em diversas sociedades. Nesse capítulo, integra ainda suas proposições com a teoria do Self Dialógico (Hermans, Kempen, \& Loon, 1992), aspecto já anunciado no Capítulo 3.

O Capítulo 5 apoia-se em uma das noções nucleares do pensamento de Valsiner: a da indeterminação limitada, cunhada por ele em suas proposições acerca da impossibilidade e inadequação de proposições deterministas para abordar os fenômenos de desenvolvimento:

O curso principal do desenvolvimento é deterministicamente indeterminista: os sistemas de canalização passíveis de especificação (que em dado momento representam o estado determinístico do processo de desenvolvimento) são a base para as "surpresas" - construções novas (que representam o lado não determinístico do desenvolvimento). Essa indeterminação limitada garante estabilidade e instabilidade, continuidade e mudança, e rigidez e flexibilidade no desenvolvimento (Valsiner, 1997, p. 323).

Por isso, nesse capítulo, Valsiner dirá que os ambientes humanos são ambientes socialmente sugestivos em contraposição à ideia de determinação da pessoa pelo ambiente. Distintos significados codificados por diferentes instituições sociais, com propósito de orientação social, 
sugerem à pessoa maneiras de agir, que elas selecionarão em função desse ou daquele critério de valor.

Valsiner retoma nesse capítulo que agir é agir simbolicamente, assim como é para Boesch (1991). Tanto um quanto outro usam a metáfora do movimento, em que a pessoa vai de um lugar a outro, simbolicamente, cruzando fronteiras, ou sendo cerceada por barreiras que são, elas próprias, culturalmente construídas, já que a cultura é construção semiótica. Podemos dizer que tanto em Valsiner como em Boesch, fronteiras, barreiras e limiares são construídos pelos processos de internalização e externalização, são momentaneamente estáveis, incitando e sugerindo mobilidade simbólica pessoal. "Quando criamos fronteiras, tanto interna quanto externamente, criamos também a possibilidade de ultrapassá-las" (p. 197). Ou, como havia dito anteriormente, "Somos todos migrantes" (Valsiner, 2007b).

No Capítulo 6, o autor se dedica ao pensamento orientado, por um lado, por aquelas sugestões sociais que vinha abordando no capítulo anterior e, por outro, por aquelas que ocorrem no nível privado e oculto. Mais ainda, "[é] no pensamento humano que o social e o pessoal encontram-se unidos dentro de um processo cultural (semiótico) de construir sentido do mundo e de si mesmo" (p. 231). Estamos aqui no âmbito da construção que o autor faz apoiado nas relações entre pensamento e linguagem no caminho aberto por Vygotsky. Ao se profundar nesse caminho, Valsiner dará primazia à abdução como processo de raciocínio ligado à inovação, comparativamente aos processos indutivo e dedutivo.

Entretanto, "a vida psicológica humana, em sua forma mediada por signos, é afetiva em sua natureza" (p. 251, ênfase do autor). O domínio cognitivo constitui uma ferramenta semiótica emergente para organizar o relacionamento afetivo com o mundo. Ele abordará a centralidade da vida afetiva na construção das culturas pessoais no Capítulo 7, apresentando um modelo hipotético da hierarquia dos níveis de mediação semiótica dos processos afetivos, em que os fenômenos da afetividade humana estão organizados em diferentes níveis, nos quais a emoção e os sentimentos apresentam diferentes graus de generalidade.

Chega-se, então, ao Capítulo 8, em que Valsiner proporá uma reconstrução metodológica da psicologia baseada na perspectiva idiográfica e sistêmica da psicologia cultural. Criticando o reducionismo, em psicologia, das opções metodológicas a um único método, e apontando a inabilidade que esse caminho gera para o estudo de processos dinâmicos complexos, o autor discute e defende a metodologia de pesquisa como processo de construção de conhecimento.

A metodologia dependerá, então, primordialmente "das estratégias gerais que definem para onde olhar, quais comparações fazer, e o que assumir sobre os fenômenos antes que as práticas analíticas efetivas sejam postas em prática" (p. 301, ênfase do autor). É entendida segundo o modelo de um processo helicoidal, onde a ênfase está na subjetividade do pesquisador, na medida em que este experimenta os fenômenos e reflete sobre eles de maneira intuitiva, em conexão com os seus axiomas básicos sobre os fenômenos, construindo teorias a partir da sua perspectiva pessoal. "Os cientistas não são autômatos racionais, mas seres humanos subjetivos, pessoalmente envolvidos, com preferências subjetivas e posições, a partir das quais consideram os assuntos de sua pesquisa" (p. 301). Assim, a objetividade só pode ser alcançada pela via da subjetividade; ou seja, a objetividade científica emerge fundada sobre um processo de generalização profundamente subjetivo.

Dessa maneira, esse livro propõe e discute o sentido das noções de causalidade, experimento, dados e generalidade desde a perspectiva da psicologia cultural que veio construindo; uma psicologia que deve dar conta de compreender a generalidade dentro de particulares sempre únicos, os significados e padrões de ação criados pelos seres humanos para enfrentar a indeterminação inerente ao futuro. Futuro também da Psicologia.

\section{Referências}

Boesch, E. E. (1991). Symbolic action theory and cultural psychology. New York: Springer.

Hermans, H. J. M, Kempen, H. J. G., \& van Loon, R. J. P. (1992). The dialogical self: Beyond individualism and rationalism. American Psychologist, 47(1), 23-33.

Valsiner, J. (1987). Culture and the development of children's action. Chichester: Wiley.

Valsiner, J. (1989). Human development and Culture.

Valsiner, J. (1998). The guided mind. Cambridge, MA: Harvard University Press.

Valsiner, J, (2000). Culture and human development.

Valsiner, J. (2007a). Culture in mind and societies. New Delhi: SAGE.

Valsiner, J. (2007b). Human development as migration: Striving towards the unknown. In L. M. Simão \& J.
Valsiner (Orgs.), Otherness in question: Labyrinths of the self (pp. 349-378). Charlotte, NC: Information Age Publishing.

Valsiner J. (2012). A guided science: History of psychology in the mirror of its making. New Brunswick, NJ: Transaction.

Valsiner, J. (2014). An invitation to cultural psychology. London: Sage.

Van der Veer, R., \& Valsiner, J. (2000). The social mind: Construction of the idea. New York: Cambridge University Press. 